\title{
FORECASTING OF FORMATION OF PHARMACEUTICAL GLASS WASTE TAKING INTO ACCOUNT THE COVID-19 DATABASE
}

\author{
Antonina Baranova ${ }^{1}$, Nataliia Samoilenko ${ }^{2}$, Inna Pitak ${ }^{3}$ \\ ${ }^{1} 1$ Department of chemical engineering and industrial ecology, National Technical University «Kharkiv Polytechnic Institute», Kharkiv, \\ Ukraine \\ ${ }^{2}$ Department of chemical engineering and industrial ecology, National Technical University «Kharkiv Polytechnic Institute», Kharkiv, \\ Ukraine

Subject of research: forecasting the formation of pharmaceutical glass waste in medical institutions, taking into account the peculiarities of the use of medicines during the COVID-19 epidemic in Ukraine.

Section:

Waste Management and Disposal

Research problem: Predicting the formation and accumulation of pharmaceutical glass waste in hospitals in order to implement effective environmental management and deter-

DOI mine the resource possibilities for further waste disposal.

$10.21303 / 2313-8416.2020 .001392$ Main scientific results: A model has been developed that can be used to predict the generation of pharmaceutical waste from glass in hospitals in the country during an ep-

KEYWORDS idemic, as well as in the presence of the necessary input data in a non-epidemic period.

pharmaceutical glass waste hospitals Based on regression analysis and using the Minitab-19 software, the dependences of the volume of pharmaceutical waste from glass on three variable factors were determined. Using statistical data on the incidence of COVID-19 in Ukraine, using the developed model, the PGW volume in the Volyn region for a given period of time was calculated. The scope of practical application of the research results: planning of measures to improve the environmental safety of handling pharmaceutical glass waste; development of business models for the disposal of this waste.

An innovative technological product: the predictive model helps to identify the resource possibilities of using pharmaceutical glass waste for industrial waste disposal.

Scope of application of the innovative technological product: medical waste management, industrial disposal of pharmaceutical glass waste.

(C) The Author(s) 2020. This is an open access article under the CC BY license http://creativecommons.org/licenses/by/4.0).

\section{Introduction}

\section{1. The object of research}

The object of research is to predict the formation of pharmaceutical glass waste in hospitals, taking into account the peculiarities of the use of medicines during the COVID-19 epidemic in Ukraine.

\section{2. Problem description}

The volume of medical waste all over the world is growing steadily, and during the period of epidemics of infectious diseases it becomes especially important. The current COVID-19 epidemic, which is projected to continue for years [1], has already generated an extremely large amount of infected medical waste. Among them, in terms of volume, pharmaceutical waste from glass is distinguished, which is used after medical procedures glass ampoules and vials.

In existing models of medical waste generation, attention is drawn to the classification of waste by hazard [2], dependence of a medical institution on the form of ownership (public or private sector), type of patient treatment, level of patient care [3], number of wards and beds, staff and 
inpatients [4]. At the same time, the results of calculations carried out on the creation of medical waste during the treatment of patients in medical institutions are quite different, which makes it difficult to predict the accumulation of waste, planning measures for environmental safety and waste disposal. In an epidemic, the complexity of modeling the process of medical waste generation using these approaches is explained by the rapid changes in input parameters (for example, the number of wards, the level of service, etc.).

Trends in the PGW formation that are associated with COVID-19 indicate an increase in the problem of waste accumulation and the need for an early resolution of disposal issues. There are prospects for the industrial utilization of PGW in the production of ceramic tiles [5], but a reasonable forecast of the PGW volume in hospitals required for the development of a waste recycling strategy is not given.

\section{3. Method proposed to solve the problem}

To implement effective waste management, develop business models for PGW processing and reduce the negative impact of such waste on the environment, it is necessary to develop predictive models for the PGW formation, which are currently most formed during the treatment of patients in hospitals. Reliable statistical data on the number of patients with COVID-19 [6], the standard treatment protocol, the known population provides an opportunity to establish the dependence of the PGW formation on the factors of their production and use this data to create a predictive model of the PGW formation. Important for use in modeling is the approach to classifying infected waste after the decontamination procedure to the category of solid household waste, predictive models of the formation of which were developed using regression analysis [7].

\section{Materials and methods}

To implement modeling for the creation and accumulation of PGW in the process of treating patients with COVID-19 in a hospital setting, the regression analysis method was used (Minitab-19). This approach is implemented to predict the generation of solid household waste [7].

The prognosis of the accumulation of infected PGW in hospitals is considered using the example of the generation of waste ampoules and vials from which antibiotics were withdrawn, which were used in the treatment of patients with COVID-19 [8]. The calculations were based on data on the treatment of patients with the clinical form of the coronavirus with pneumonia and patients in serious condition. In the process of treating such patients, the drugs azithromycin, amoxicillin and levofloxacin were used.

\section{1. Experiments}

Regression analysis is advisable to use to analyze the change in response when the predictor changes (Minitab-19). In these studies, to determine the number of formed PGW as input variables (coefficients k), let's use:

$-x_{1}-$ number of inhabitants;

$-x_{2}-$ number of patients with COVID-19;

$-x_{3}$ - the total amount of medical waste generated in hospitals ( $\left.\mathrm{t} / \mathrm{week}\right)$.

The number of residents $\left(x_{1}\right)$ characterizes a certain percentage of the population, COVID-19 can get sick. According to data on COVID-19, people get sick regardless of age [9]. The percentage of patients by age in Ukraine is shown in Fig. 1.

According to the treatment protocol [8], all patients with clinical form of coronavirus with pneumonia and patients in serious condition are prescribed antibiotic therapy.

However, it should be noted that the age of the infected is associated with concomitant diseases. This fact indicates that additional drugs are used in the treatment, including in ampoule form. Such drugs are prescribed individually and their reception depends on the characteristics of the patient's health condition, since this condition can change unpredictably, this fact was not taken into account in this modeling. Since the course of antibiotic treatment is calculated for at least 7 days, it is advisable to use the unit of waste amount as a unit of measurement of $\mathrm{t} /$ week.

Regression examines the relationship between the response (in our case $x_{4}$ ) and predictors $\left(x_{1}, x_{2}, x_{3}\right.$, which are the input data). In general, it can be used to evaluate $2 \mathrm{k}$ variants of experi- 
mental conditions. As input variable data, let's use statistical data on patients with COVID-19 in Ukraine, which were recorded during the epidemic for 5 months.

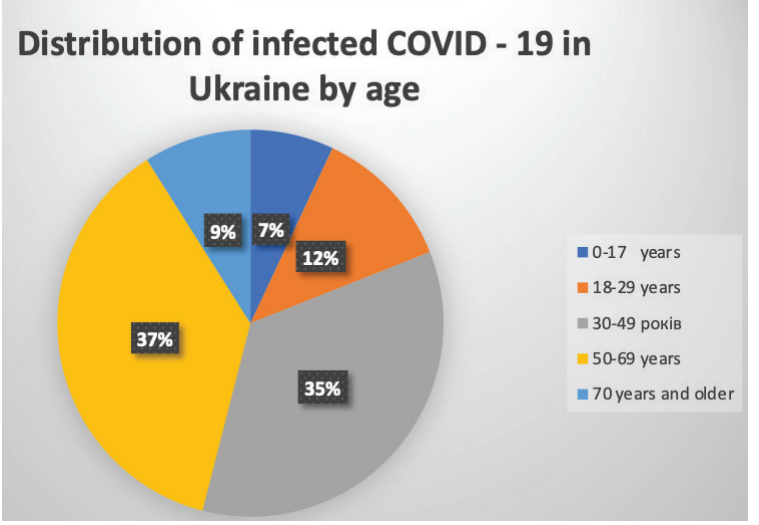

Fig. 1. Distribution of infected COVID-19 in Ukraine (by age)

When simulating the number of PGW was considered as the answer

$$
e e_{1}=f\left(x_{1} ; x_{2} ; x_{3}\right)
$$

Regression equations were developed using software (1). The algebraic representation of the regression line and the relationship between the response and predictor variables is (2).

PGW quantity:

$$
\begin{aligned}
& \text { Constan }+ \text { coef } \times \text { predictor }+ \text { coef } \times \text { predictor }+ \text { coef } \times \text { predictor, } \\
& x_{4}=-243+0.000013 x_{1}-0.000029 x_{2}+0.027751 x_{3} .
\end{aligned}
$$

This dependence shows that all predictors $\left(x_{1} ; x_{2} ; x_{3}\right)$ affect the amount of PGW generated in hospitals. The data on the construction of the model for the converted answers are presented in Table 1.

Table 1

Summary of the model for transformed answers

\begin{tabular}{cccc}
\hline S & R-sq & R-sq(adj) & R-sq(pred) \\
\hline 0.546114 & $98.36 \%$ & $98.11 \%$ & $97.64 \%$
\end{tabular}

Note: $S, R^{2}$ and adjusted $R^{2}$ are indicators of how well the model fits with reality; $S$ is the standard distance the data value falls from the regression line. The lower the $S$ value, the higher the closeness of the model to the real answer; $R-S q$ or $R^{2}$ describes the amount of change in response values that is observed. This fact is explained by the values of the predictors: the closer $R^{2}$ is to 100 , the better the results

Adjusted $\mathrm{R}^{2}$ (R-sq(adj)) is a modified $\mathrm{R}^{2}$ that has been adjusted for the number of terms in the model. This indicator is useful when comparing a model with different numbers of predictors.

$R^{2}$ is an indicator of how accurately the model predicts the response, if there are significant differences between this $R$ and two other statistics, this may indicate that the model is more accurate. In the case of calculating the PGW amount, $S=0.546, R^{2}=98.36 \%$ was obtained, which indicates a relatively high accuracy of the results, since $\mathrm{S}$ is less than $\mathrm{R}^{2}$

Table 2 presents the variance for the amount of formed PGW and presents the results of what factors should be taken into account when $P$ - values. If the regression $P=0$, then this means that at least one of the coefficients is different from 0.Analysis of the formation of PGW factors $x_{1}$ (number of people), $x_{2}$ (number of patients with COVID 19), factor $x_{3}$ (the amount of waste generated in hospitals) are to meaningful. 
Table 2

Analysis of variance for transformed responses $x_{4}$ (pharmaceutical waste glass)

\begin{tabular}{ccccc}
\hline Source & DF & Adj SS & Adj MS & F-Value \\
\hline Regression & 3 & 357.257 & 119.086 & 399.29 \\
X1 & 1 & 0.298 & 0.298 & 0.000 \\
X2 & 1 & 0.298 & 0.298 & 1.00 \\
X3 & 1 & 356.660 & 356.660 & 1195.88 \\
Error & 20 & 5.965 & 0.298 & 0.000
\end{tabular}

Total errors $\quad 23 \quad 363.222$

Note: Adj SS adjusted sums of squares; Adj MS - adjusted mean squares; F-Value-value, calculated by dividing the MS multiplier by the MS error

\section{Results}

In the calculations to determine the PGW number, a hypothetical situation was considered in which a third of the population of Ukraine could be ill with COVID-19. Therefore, it was assumed that $x_{1}=13943.86$ thousand people. According to statistical data, the population from March 2020 to July 2020 ranged from 41858.1 thousand people - 41805.1 thousand people The total amount of medical waste generated in hospitals is 30-33 thousand tons/month [10].

The number of COVID-19 patients in Ukraine in the period from March 2020 to July 2020 increased from 669 to 23797 patients during this period per month. The total number of cases is 68794 people.

Fig. 2 shows the dependence of the PGW formation on variable factors. The calculation result indicates that the most significant factor for the PGW formation $\left(x_{4}\right)$ is the total amount of medical waste generated in hospitals $\left(x_{3}\right)$.

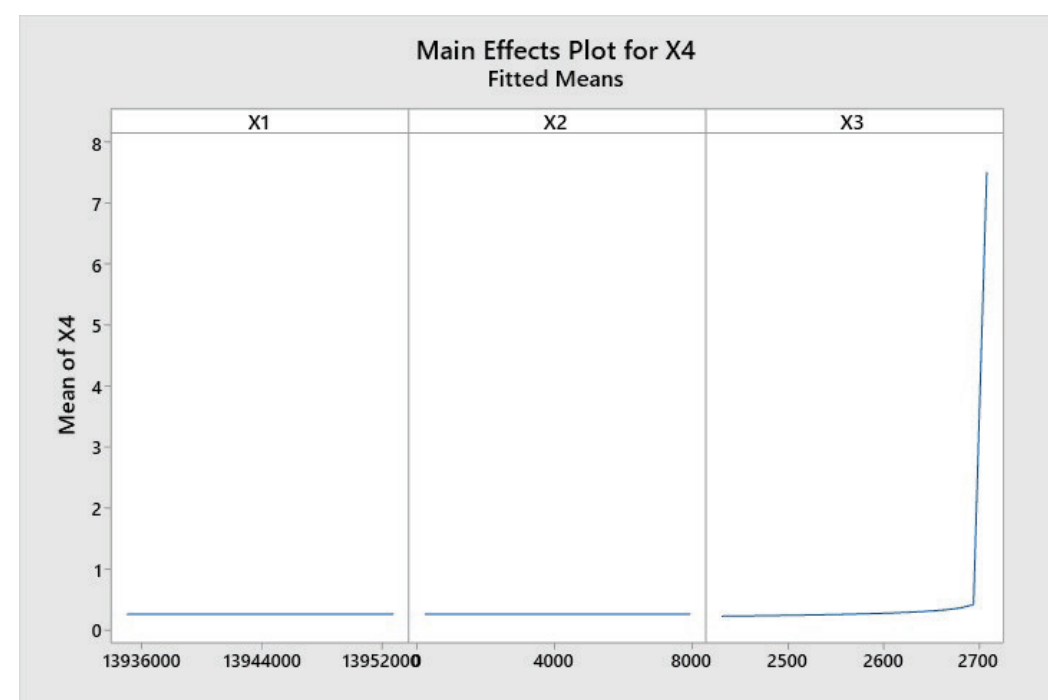

Fig. 2. The amount of PGW formation $\left(x_{4}\right)$ depending on the number of residents $\left(x_{1}\right)$, the number of COVID patients $\left(x_{2}\right)$ and the total amount of medical waste in hospitals

The surface area $x_{4}=f\left(x_{2}, x_{3}\right)$ is shown in Fig. 3. It shows the dependence of the PGW formation $\left(x_{4}\right)$ on the number of cases of COVID-19 $\left(x_{2}\right)$ and the total amount of medical waste $\left(x_{3}\right)$. The determination was carried out with a population of 13943.86 thousand people.

The contour diagram based on the model equation (Fig. 4) represents in two dimensions the functional relationship between the response and the variables. 
It is shown how the variable $x_{4}$ (the amount of PGW formation) is related to two variables: $x_{2}$ (the number of patients with COVID-19) and $x_{3}$ (the total amount of medical waste). Variable $x_{1}$ remains constant (13943866.5 people).

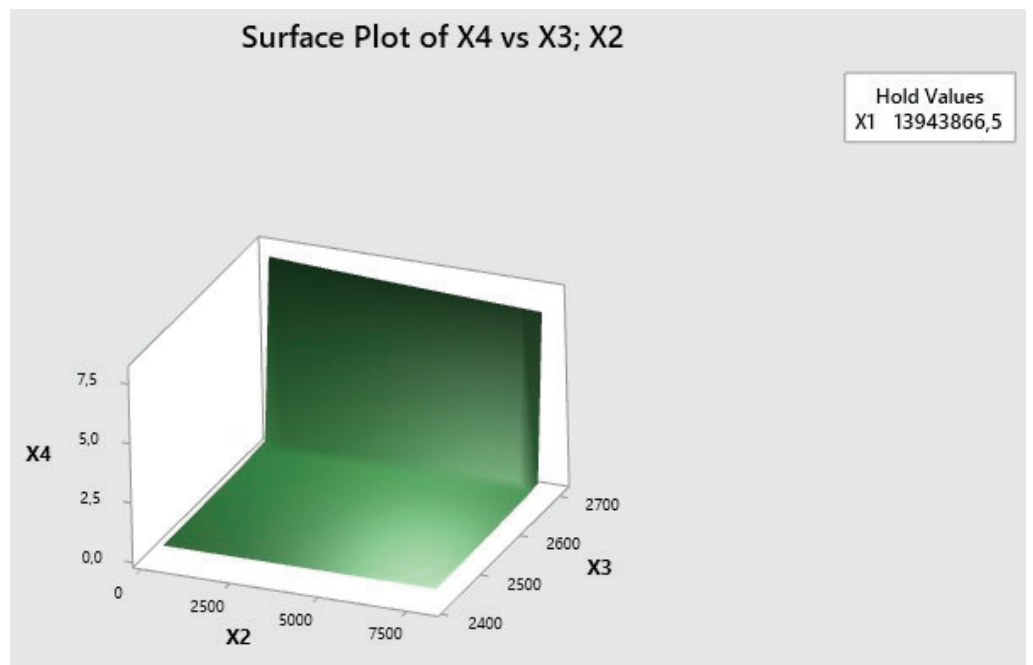

Fig. 3. Surface area of the amount of PGW formation $\left(x_{4}\right)$ depending on $\left(x_{2}\right)$ the number of patients with COVID-19 and $\left(x_{3}\right)$ the total amount of medical waste

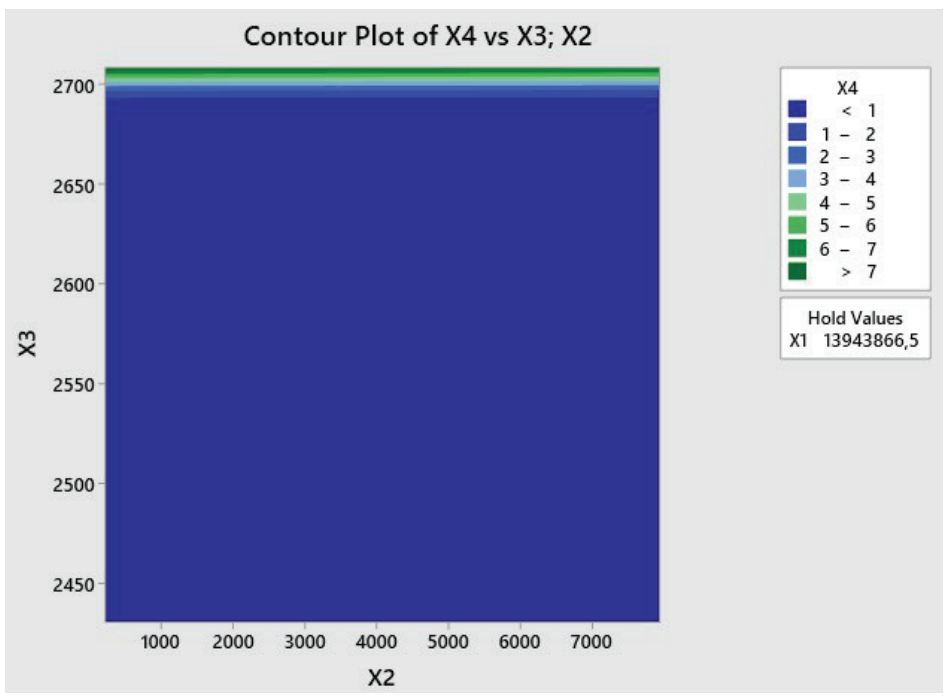

Fig. 4. Dependence of the formation of the PGW number $\left(x_{4}\right)$ on the number of patients with COVID-19 $\left(x_{2}\right)$ and the total volume of medical waste $\left(x_{3}\right)$

The blue area shows the outline where the waste is smallest and the dark green area is the largest.

Currently, the statistical analysis of COVID-19 diseases is relevant for Ukraine, taking into account the peculiarities of its distribution in certain territories, which are assigned the status of a certain level of danger [11]. These levels, including those characterizing the number of patients undergoing treatment in a hospital.

Using the developed model, using the example of the Volyn region, the dependence of the PGW amount $\left(y_{4}\right)$ on the number of patients with COVID-19 in the region $\left(y_{2}\right)$ and the total amount of medical waste generated in hospitals in this region ( $\mathrm{t} /$ week) $\left(y_{3}\right)$ was established.

Fig. 5 shows the surface area of the dependence of the PGW formation $\left(y_{4}\right)$ on the number of patients with COVID-19 $\left(y_{3}\right)$ and the total amount of medical waste $\left(y_{2}\right)$.

The light green area shows the outline where the waste will be the least, and the dark green indicates the outline where the waste will be greatest. 


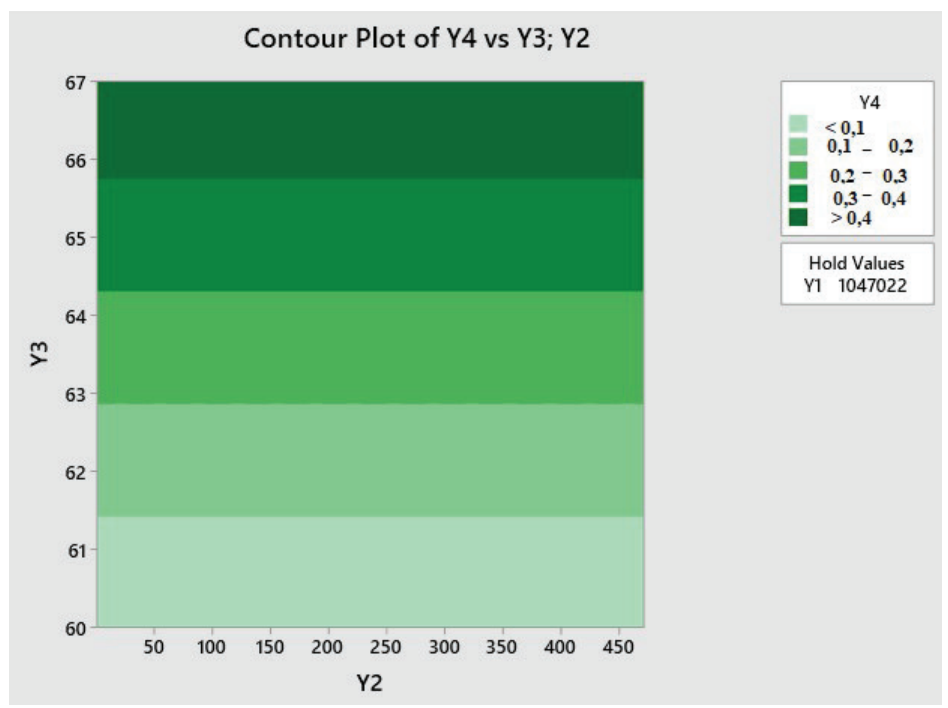

Fig 5. Surface area of the dependence of the PGW formation $\left(y_{4}\right)$ on the number of patients with COVID-19 $\left(y_{3}\right)$ and the total amount of medical waste $\left(y_{2}\right)$ (data as of 01.08.2020)

\section{Discussion}

During the COVID-19 epidemic, there is an extremely acute problem of the increased generation of infectious medical waste, which must be safely neutralized and disposed of. Analysis of publications shows that the subject of research is the volume of education of personal protective equipment, as well as disinfectants and test kits [12]. For this, the authors propose the use of descriptive statistical analysis. Also, the generation of the total amount of medical waste is carried out on the basis of analysis of literature data [13]. These publications do not cover the actual issue of the formation of pharmaceutical waste from glass in medical institutions, which are the subject of these studies.

The simulation results obtained in this study indicate a logical connection between the answer that is obtained and the variables. An accurate prediction of waste generation is one of the most important factors in practical planning. The value and ratio of indicators $S$ and $R^{2}$ indicate a relatively high accuracy of the developed model (respectively 0.546 and $98.36 \%$ ).

As a result of the modeling, the dependence of the volume of PGW formation on independent variables was determined: the number of residents, COVID can get sick - 19, the number of patients with this disease and the total amount of waste generated in hospitals. It was found that the most significant factor in the formation of PGW volumes is the total amount of medical waste generated in hospitals.

With a given constant variable of the number of residents of the country and variable values of the number of patients with COVID-19 and the total amount of medical waste, the zones of the largest and the smallest volume of the formed PGW are established.

On the example of modeling the PGW formation in the Volyn region, the practical application of the developed model for analyzing the dynamics of waste generation is shown; it is important for making decisions on environmental waste management and processing.

These studies were limited by the lack of information on the creation of the total amount of medical waste, which is determined by the timing of statistical reporting.

\section{Conclusions}

Based on relational analysis using the Minitab-19 software, a model for the PGW formation in hospitals in Ukraine has been developed. Given the particular urgency of the problem of PGW accumulation during an epidemic, the modeling was carried out on the basis of reliable statistical information on the incidence of COVID-19 in the country. It has been established that the amount of PGW formation mainly depends on the total amount of medical waste generated in hospitals.

The developed model is characterized by accuracy and is fundamental for its application in planning and optimizing the implementation of PGW environmental management and effective waste disposal. The use of the model makes it possible to determine the volume of PGW formation 
in hospitals located on the territory of different levels of danger of the spread of the disease in the country in a given period of time. This model can be adapted to determine the generation of other components of medical waste generated in hospitals.

\section{References}

[1] Lessler, J. (2020). Coronavirus will linger after the pandemic ends. But it won't be as bad. Washington Post. Available at: https://www.washingtonpost.com/outlook/coronavirus-pandemic-immunity-vaccine/2020/03/12/bbf10996-6485-11ea-acca80c22bbee96f_story.html

[2] Serbinova, L., Fesan, H., Tymoshchuk, O. (2017). Justification of feasibility of medical waste recycling and processing by incineration at the healthcare facilities. Visnyk KrNU imeni Mykhaila Ostrohradskoho, 5 (106), 136-142.

[3] Al-Khatib, I. A., Eleyan, D., Garfield, J. (2016). A system dynamics approach for hospital waste management in a city in a developing country: the case of Nablus, Palestine. Environmental Monitoring and Assessment, 188 (9). doi: https://oi.org/ 10.1007/s10661-016-5487-9

[4] Golbaz, S., Nabizadeh, R., Sajadi, H. S. (2019). Comparative study of predicting hospital solid waste generation using multiple linear regression and artificial intelligence. Journal of Environmental Health Science and Engineering, 17 (1), $41-51$. doi: https://doi.org/10.1007/s40201-018-00324-z

[5] Samoilenko, N., Shchukina, L., Baranova, A. (2019). Development of engobe composition with the use of pharmaceutical glass waste for glazed ceramic granite. Eastern-European Journal of Enterprise Technologies, 4 (10 (100)), 6-12. doi: https:// doi.org/10.15587/1729-4061.2019.175922

[6] COVID - 19 Coronavirus pandemic (2020). Available at: https://www.worldometers.info/coronavirus/

[7] Ghinea, C., Drăgoi, E. N., Comăniţă, E.-D., Gavrilescu, M., Câmpean, T., Curteanu, S., Gavrilescu, M. (2016). Forecasting municipal solid waste generation using prognostic tools and regression analysis. Journal of Environmental Management, 182, 80-93. doi: https://doi.org/10.1016/j.jenvman.2016.07.026

[8] Tymchasovi metodychni rekomendatsiyi «Diahnostyka, likuvannia, profilaktyka uskladnen, intensyvna terapiia koronavirusnoi infektsiyi» (2019 nCoV) (2020). Kyiv.

[9] Koronavirus v Ukraini (2020). Available at: https://index.minfin.com.ua/reference/coronavirus/ukraine/

[10] Safranov, T., Shanina, T., Panchenko, T. (2015). The problem of medical waste classification and treatment in Ukraine. Visnyk Odeskoho derzhavnoho ekolohichnoho universytetu, 19, 6-11.

[11] Postanova Kabinetu Ministriv Ukrainy No. 641 pro vstanovlennia karantynu ta zaprovadzhennia posylenykh protyepidemichnykh zakhodiv na terytoriyi iz znachnym poshyrenniam hostroi respiratornoi khvoroby COVID-19, sprychynenoi koronavirusom SARS-CoV-2 (2020). Kyiv. Available at: https://www.kmu.gov.ua/npas/pro-vstanovlennya-karantinuta-zapr-641

[12] Abu-Qdais, H. A., Al-Ghazo, M. A., Al-Ghazo, E. M. (2020). Statistical analysis and characteristics of hospital medical waste under novel Coronavirus outbreak. Global Journal of Environmental Science and Management, 6, 21-30. doi: http:// doi.org/10.22034/GJESM.2019.06.SI.03

[13] Prihartanto (2020). Perkiraan timbulan limbah medis bahan berbahaya Dan beracun (b3) dari rumah sakit penanganan pasien COVID-19. Jurnal Sains dan Teknologi Mitigasi Bencana, 15 (1), 12-18. 